\title{
Circumstances in which colonoscopy misses cancer
}

Linda Rabeneck, ${ }^{1-3}$ Lawrence F Paszat ${ }^{2,3}$

'Department of Medicine, University of Toronto, Toronto, Canada

${ }^{2}$ Department of Health Policy, Management and Evaluation, University of Toronto, Toronto, Canada

${ }^{3}$ The Dalla Lana School of Public Health, University of Toronto,

Toronto, Canada

\section{Correspondence to} Dr L Rabeneck, Sunnybrook Health Sciences Centre, 2075 Bayview Avenue, Room T2-025, Toronto M4N 3M5, Canada; linda.rabeneck@sunnybrook.ca
Colonoscopy is associated with a varying risk of missing colorectal cancer (CRC). The objective of this paper was to review the existing evidence that indicates when colonoscopy may miss cancer in usual clinical practice and to provide information that would be helpful to endoscopists in their daily practice. CRC is diagnosed within 3 years in about $5 \%$ of persons with CRC who undergo colonoscopy in whom the cancer is not detected. Future research should be directed at disentangling the relative contributions of tumour biology and colonoscopy quality in explaining this result. When consent is obtained for colonoscopy, patients must be informed of the small risk that a cancer may not be detected. Steps that can be taken to address colonoscopy quality include formal training in colonoscopy and polypectomy technique, coupled with maintenance of skills by performing at least 300 colonoscopies per year. The use of split dose bowel preparation is advised. Colonoscopy should be completed to the caecum with documentation of landmarks (ileocaecal valve; appendiceal orifice). Careful colonoscopy technique includes examining the proximal sides of flexures and folds, washing and suctioning debris and ensuring adequate colonic distension. Caecal intubation and adenoma detection rates should be reported and reviewed. Lesions should be completely removed at polypectomy and attention given to appropriate surveillance.

\section{Introduction}

Colorectal cancer (CRC) is the fourth most common cause of cancer and the third most common cause of cancer deaths in the world, accounting for $10 \%$ of all cancer deaths. ${ }^{1}$ If it is found at an early stage, CRC is curable. In some jurisdictions, colonoscopy is used for initial screening of persons at average risk for CRC. In other jurisdictions, colonoscopy is used to follow-up an abnormal initial (non-invasive) screening test, such as a faecal occult blood test. Colonoscopy is the standard of care for diagnostic workup in persons with large bowel symptoms and for surveillance after previous colorectal neoplasia. Given the central role of colonoscopy in CRC screening, diagnostic work-up and surveillance, it is important that the procedure is as accurate as possible. However, colonoscopy is associated with a varying risk of missing CRC. The objective in this paper is to summarise existing evidence on circumstances in which colonoscopy has not detected CRC but a CRC is diagnosed prior to the recommended time of subsequent colonoscopy, and to indicate how endoscopists can make use of this information in clinical practice.

\section{Nomenclature}

We recommend the use of a term to describe CRC that is not detected at colonoscopy-but is diagnosed prior to the recommended subsequent colonoscopy-that is applicable to all colonoscopies regardless of the indication for the procedure. It is often not possible to be certain that a CRC that was not detected at the time of colonoscopy-but is subsequently diagnosed-was in fact a missed cancer or whether it was a new cancer that was not present at the time of the colonoscopy but arose and grew quickly following the procedure. For this reason, it may be more accurate to refer to the diagnosis of CRC following a colonoscopy in which the cancer was not detected, as postcolonoscopy CRC (PCCRC).

A key advantage of the term PCCRC is that it does not imply or assume a mechanism (eg, whether the cancer was new or missed) as most often this is unknown. In addition, the associated time period in which the PCCRC is diagnosed following the colonoscopy (eg, 1 year, 3 years, 5 years) can be specified, to facilitate comparisons across studies. For example, this could be denoted as PCCRC (1 year). Furthermore, the term PCCRC could be used regardless of the indication for the colonoscopy (eg, screening, diagnostic, 
all) as long as the indication is specified, to facilitate comparisons. The term PCCRC will be used in this paper.

\section{How frequent is PCCRC?}

Data from patients who undergo colonoscopic surveillance following removal of adenomas indicate that PCCRCs are diagnosed in a small but clinically important proportion of patients following colonoscopy. In the National Polyp Study, colonoscopy and polypectomy were performed in an adenoma bearing cohort at baseline. During 5.9 years of follow-up, six CRCs were detected in 1375 patients (0.6 per 1000 person years of follow-up). ${ }^{2} \mathrm{~A}$ recent pooled analysis of data from eight North American studies, including the National Polyp Study, comprising 9167 men and women aged 22-80 years with previous adenoma removal, estimated the risk of subsequent advanced neoplasia (AN). During a median 4 year follow-up, PCCRC occurred in 1 in $150(0.6 \%)$ persons. ${ }^{3}$ A nationwide study from the Netherlands estimated PCCRC incidence following adenoma removal in usual practice ${ }^{4}$ during 1988-1998. In that study, 78473 adenoma patients were followed for a mean of 4.5 years after first adenoma removal. The first year after polypectomy these individuals had a significantly higher risk of CRC than the general population. The standardised incidence rate declined to 1.1 (95\% CI 0.9 to 1.2 ) beyond 5 years of follow-up. The authors hypothesised that the high risk of PCCRC in years 1-5 was due to cancers missed at the first adenoma removal. ${ }^{4}$

Two studies have estimated that among persons with CRC who undergo colonoscopy, the percentage with a PCCRC within 3 years is 5\%. A retrospective study from 20 Indiana hospitals that reported $47(5 \%)$ of 941 CRC patients who had a colonoscopy within 3 years prior to their diagnosis had a reportedly normal colonoscopy. ${ }^{5}$ In addition, an Ontario population based cohort study of 12487 persons with CRC reported that $2-6 \%$ had a PCCRC within 3 years of colonoscopy, with right-sided CRC associated with a greater risk. ${ }^{6}$

\section{Colonoscopy is less effective in the right colon}

Recent evidence indicates that in usual clinical practice, colonoscopy is less effective for lesions in the proximal colon. A population based cohort study of 39375 individuals of all ages from Manitoba reported that negative colonoscopy was associated with a standardised incidence rate for CRC of 0.28 (95\% CI 0.09 to 0.65 ) at 10 years. $^{7}$ In that study, the proportion of incident CRCs in the proximal colon was higher in the negative colonoscopy cohort than in the Manitoba population ( $47 \%$ vs $28 \%$, respectively). ${ }^{7}$ In addition, an Ontario study of 110402 individuals with a negative complete colonoscopy reported a sustained reduction in incident CRC overall and incident distal CRC for up to 14 years following the procedure. ${ }^{8}$ In the proximal colon however, the reduction in incidence differed in magnitude and timing, and was observed in about half of the 14 follow-up years, and for the most part occurred after 7 years of follow-up. ${ }^{8}$ Furthermore, an Ontario case control study of 10942 patients with CRC and 51460 controls reported that colonoscopy was associated with decreased overall CRC mortality but this association was primarily due to lower mortality from left-sided cancers. ${ }^{9}$ For example, complete colonoscopy was strongly associated with lower mortality from left-sided (OR 0.33, 95\% CI 0.28 to 0.39 ) but not right-sided (OR 0.99, 95\% CI 0.86 to 1.14 ) CRC. Finally, a statewide German study of 3287 screening colonoscopy participants evaluated the association of AN and receipt of colonoscopy in the previous 10 years. ${ }^{10}$ In that study, the adjusted prevalence ratios for AN were: overall 0.52 (95\% CI 0.37 to 0.73 ), right-sided 1.05 (95\% CI 0.63 to 1.76) and left-sided 0.33 (95\% CI 0.21 to $0.53)$. Taken together, these studies provide consistent evidence that colonoscopy is less effective for lesions in the proximal colon in usual clinical practice.

There are several possible explanations for this finding. One possibility is the unique molecular characteristics that have been observed in proximal lesions, which may be associated with more rapid growth. Another possibility is the different morphological characteristics of proximal lesions that may be associated with more difficulty in detection. For example, flat lesions, which can be more readily missed at colonoscopy, may be more common in the proximal colon. Furthermore, the reduced effectiveness of colonoscopy may be related to aspects of colonoscopy quality, such as inadequate bowel 
preparation or failed caecal intubation. Future research should be directed at disentangling the relative contributions of tumour biology and colonoscopy quality in explaining these results. Regardless of their explanation, these results highlight an important limitation of colonoscopy in usual clinical practice.

\section{Factors associated with PCCRC}

The Ontario study that estimated the percentage of PCCRCs reported that compared with men, women were at increased risk for PCCRC. ${ }^{6}$ In addition, in both men and women, older age, a history of diverticular disease, having right-sided or transverse CRC and having a colonoscopy done in an office were independently associated with PCCRC. ${ }^{6}$ Furthermore, in women, a previous history of abdominal or pelvic surgery was also independently associated with a risk of PCCRC while in men excision of one or more polyps during colonoscopy was independently associated with a decreased risk of PCCRC. ${ }^{6}$

There is growing documentation that the specialty of the endoscopist, which is a proxy for formal training and greater experience, is an important factor. Having colonoscopy performed by a gastroenterologist is associated with a lower risk of PCCRC. For example, in the previously cited Ontario study of 12487 persons with a new diagnosis of CRC, compared with having the colonoscopy performed by a gastroenterologist, having the procedure performed by an internist or family physician was independently associated with an increased risk of PCCRC. ${ }^{6}$ In addition, in the Ontario cohort study of 110402 persons who had a negative complete colonoscopy, those who had their procedures performed by a gastroenterologist were less likely to be diagnosed with CRC over a 15 year follow-up period. ${ }^{11}$ The Manitoba study reported a nonsignificant trend towards general practitioners performing a higher proportion of the colonoscopies in persons with a subsequent PCCRC. ${ }^{7}$ Finally, in the US study from Indiana, the risk of PCCRC was higher for non-gastroenterologists compared with gastroenterologists. ${ }^{5}$

\section{Reasons for PCCRC}

The cancer was not seen

Given our current technology, there are several possible reasons why a CRC might not be seen at colonoscopy. Firstly, the lesion may not be reached during the procedure. There are several reports of large scale $(>5000)$ studies of colonoscopy that have estimated the rates of caecal intubation. In a study of 331608 colonoscopies in Ontario during 1999-2003, a caecal intubation rate of $86.9 \%$ was reported. ${ }^{12}$ Patients with incomplete colonoscopy were more likely to be older, more likely to be female and have a history of prior abdominal surgery or prior pelvic surgery. ${ }^{12}$ In an audit of 9223 colonoscopies performed in three regions in the UK published in 2004, a caecal intubation rate of $76.9 \%$ was reported. ${ }^{13}$ In a US report of 5477 colonoscopies performed by gastroenterologists at an academic hospital during 1995-2005, the caecal intubation rate was $85.1 \% .{ }^{14} \mathrm{~A}$ study of 50148 colonoscopies performed in Poland during 2000-2004 reported a caecal intubation rate of $91.1 \% .{ }^{15}$ Taken together, these results illustrate that incomplete colonoscopy is an issue in clinical practice.

The US Multi-Society Task Force on CRC has set targets of $\geq 90 \%$ caecal intubation in all cases and $>95 \%$ in screening cases, and states that caecal intubation should be documented and that visualisation of the lips of the ileocaecal valve and the appendiceal orifice are the best landmarks to use. ${ }^{16}$ Incomplete colonoscopy may explain why proximal (rightsided) cancers were more likely to not be seen than lesions in the rectum or sigmoid colon. This could occur because the endoscopists believed that they had inserted the endoscope to the caecum when in fact they had not. Reaching the caecum is more technically challenging than reaching the distal colon.

Secondly, a cancer may not be seen because the bowel preparation was not adequate and the mucosa was not fully visualised. The right colon is more difficult to clean. ${ }^{17}$ The use of split dose preparation-in which half of the preparation is taken on the evening before colonoscopy and the other half on the day of the procedure-provides superior mucosal visualisation. ${ }^{18}$ This may be because the quality of bowel preparation varies inversely with the duration of the interval between the last dose of the agent and the start of colonoscopy. ${ }^{19}$ Colonoscopies performed within $14 \mathrm{~h}$ after the last dose 
of the agent were better prepped than those performed after 14 h. ${ }^{19}$

Thirdly, the cancer may not be seen because of inadequate technique. Findings from studies of CT colonography followed by colonoscopy have shown that in the case of polyps, most adenomas $>6$ $\mathrm{mm}$ that are missed at colonoscopy are located on the proximal side of a fold or near the anal verge. ${ }^{20}$ Whether new colonoscopy techniques will enhance lesion detection is currently an important question. Studies are needed to evaluate the potential role of enhanced colonoscopy techniques, such as wide angle colonoscopes and narrow band imaging, in clinical practice.

\section{Prior incomplete polypectomy}

Polypectomy is the key to reducing CRC incidence following colonoscopy. Despite the central role of polypectomy, there is variation in technique coupled with clear evidence that incomplete polypectomy may lead to missed cancer. In a 14 year follow-up study from St Mark's Hospital that began 2 years after 1618 persons underwent rigid sigmoidoscopy and polypectomy during 1957-1980, the incidence of subsequent rectal cancer was strongly associated with a history of incompletely excised sessile adenoma. ${ }^{21}$ In a retrospective study of 830 persons with a CRC at a US VA hospital, 45 were diagnosed within 5 years of a complete colonoscopy. $^{22}$ In these PCCRCs, onequarter $(27 \%)$ developed at the site of a previous polypectomy. A retrospective study reported results from 2079 patients with adenomas who had a baseline clearing colonoscopy followed by a second clearing colonoscopy at 1 year and then surveillance colonoscopy at 4 years. ${ }^{23}$ In $4 / 13$ (31\%) patients in whom PCCRC was diagnosed, the cancer was attributed to incomplete removal of a previous adenoma. ${ }^{23}$

\section{Rapid growth}

Finally, some rapidly progressing cancers may not have been present at colonoscopy which may have been truly negative. The polyp-cancer hypothesis describes the slow evolution of CRC from adenomatous polyps. ${ }^{24}$ According to the polyp-cancer paradigm, detection and removal of adenomatous polyps-before they become cancers-leads to a reduction in CRC incidence and subsequently a reduction in CRC deaths. In other words, we expect that clearing the colon and rectum of polyps will reduce the risk of CRC. However, it is recognised that the polyp-cancer sequence is not the only biological pathway for the development of CRC. There are likely several pathways.

An alternate pathway in which cancers may arise from mucosa that appears grossly endoscopically normal (or from a very small premalignant lesion) and grow rapidly, involves inactivation of a mismatch repair (MMR) gene. MMR gene inactivation is estimated to account for about $15 \%$ of sporadic CRCs. MMR gene inactivation can be detected by examining the cancer tissue for microsatellite instability (MSI). A retrospective study compared the frequency of MSI in cancer tissue of 51 persons with PCCRCs that were diagnosed within 5 years of a complete colonoscopy in which all visible polyps were removed and 112 patients with CRCs that were detected at the time of colonoscopy (detected cancers). ${ }^{25}$ MSI was detected in 30.4\% of PCCRCs compared with $10.3 \%$ of detected cancers. After adjusting for age, PCCRCs were 3.7 times more likely than detected CRCs to be MSI+. The PCCRCs were more likely to be in the proximal colon and were smaller than detected CRCs. Findings such as these suggest that tumour biology may in part explain PCCRC.

\section{Flat lesions}

Flat lesions, which are more difficult to detect using standard (non-enhanced) colonoscopy techniques, may be more common than previously recognised. In a prospective study in the UK, 1000 patients who underwent diagnostic or surveillance colonoscopy were examined by a single endoscopist using a magnifying colonoscope and dye spraying. In that study, $36 \%$ of adenomas detected were flat; flat lesions $>1 \mathrm{~cm}$ were more likely than protruded lesions of similar size to harbour severe dysplasia or invasive cancer. ${ }^{26}$ A US colonoscopy study of 1819 (largely) male veterans reported a $9.4 \%$ prevalence of non-polypoid (flat and depressed) colorectal neoplasia. ${ }^{27}$ The investigators used indigo carmine dye to spray the mucosa to assist in the detection of these lesions at colonoscopy. It seems likely that flat lesions 
Table 1 Postcolonoscopy colorectal cancer (PCCRC)

\begin{tabular}{|c|c|}
\hline $\begin{array}{l}\text { Malleable causes } \\
\text { of PCCRC }\end{array}$ & Potential solutions \\
\hline \multirow[t]{3}{*}{$\begin{array}{l}\text { Endoscopist inexperience/ } \\
\text { skill }\end{array}$} & $\begin{array}{l}\text { Ensure adequate annual } \\
\text { volume }\end{array}$ \\
\hline & Careful technique \\
\hline & Quality assurance \\
\hline Incomplete colonoscopy & $\begin{array}{l}\text { Repeat colonoscopy } \\
\text { (or CT colonography) }\end{array}$ \\
\hline $\begin{array}{l}\text { Inadequate bowel } \\
\text { preparation }\end{array}$ & Use split dose preparation \\
\hline \multirow[t]{2}{*}{$\begin{array}{l}\text { Inadequate treatment of } \\
\text { advanced neoplasia }\end{array}$} & $\begin{array}{l}\text { Careful polypectomy } \\
\text { technique }\end{array}$ \\
\hline & $\begin{array}{l}\text { Appropriate } \\
\text { postpolypectomy } \\
\text { surveillance }^{36}\end{array}$ \\
\hline $\begin{array}{l}\text { Failure to recognise flat } \\
\text { lesion }\end{array}$ & $\begin{array}{l}\text { Endoscopist awareness } \\
\text { and vigilance }\end{array}$ \\
\hline $\begin{array}{l}\text { Scenarios associated } \\
\text { with increased risk (older } \\
\text { women, diverticular } \\
\text { disease, prior abdominal } \\
\text { or pelvic surgery) }\end{array}$ & As above \\
\hline
\end{tabular}

contribute to the occurrence of PCCRCs. Whether routine use of enhanced colonoscopy techniques will result in greater detection of these lesions in clinical practice remains an open question.

\section{Putting it all together: what can we do in clinical practice?}

When consent is obtained for a colonoscopy, patients must be informed of the small risk that a cancer may not be detected (table 1).

The US Multi-Society Task Force on $\mathrm{CRC}^{16}$ outlines eight factors that are required for high quality colonoscopy, four of which are important for reducing the occurrence of PCCRC: (1) appropriate training and experience, including the ability to detect and remove polyps safely; (2) complete examination to the caecum with adequate mucosal visualisation and bowel preparation; (3) appropriate follow-up of histopathological findings; and (4) appropriate recommendation for surveillance or repeat screening based on published guidelines.

In addition, based on recent evidence, the use of a split dose preparation and/or ensuring that the time interval between ingestion of the last dose of agent and colonoscopy is not longer than $14 \mathrm{~h}$ is advised. Careful technique is advised, including: examination of the proximal sides of flexures, folds, valves; washing and suctioning to clean away mucus and faecal material; adequate distension of the colon; and taking adequate time. ${ }^{28}$

As noted above, the US Multi-Society Task Force on CRC has set targets of $>90 \%$ caecal intubation in all cases and $>95 \%$ in screening cases. ${ }^{16} \mathrm{~A}$ recent study that evaluated endoscopist factors associated with PCCRC reported that the percentage of complete colonoscopies in women may have greater potential as a quality indicator than overall completeness. ${ }^{29}$ The US Multi-Society Task Force on CRC has set a target of mean withdrawal time (for those colonoscopies in which no diagnostic or therapeutic procedures are performed) of at least $6 \mathrm{~min} .{ }^{16}$ This recommendation is based on a study of 12 community gastroenterologists with wide variation in adenoma detection rates that reported an association between higher detection rates and withdrawal time greater than 6 min..$^{30}$ On the other hand, a more recent study reported no improvement in polyp detection rate following implementation of an institution-wide policy of colonoscope withdrawal time $>7$ min. ${ }^{31}$ Clearly withdrawal time is a proxy for other factors, including careful technique. A recent US study of 10136 patients with PCCRC from the Mayo Clinic reported variation in the rates of missed CRCs, and that it was the endoscopist, not withdrawal time, that was critically important. ${ }^{32}$ Some endoscopists perform better than others.

The US Multi-Society Task Force on CRC has set targets for adenoma detection for persons $>50$ years undergoing first time colonoscopies of $>25 \%$ in men and $15 \%$ in women. ${ }^{16} \mathrm{~A}$ report of results from a Continuous Quality Improvement initiative from the screening colonoscopy programme in Poland indicates that endoscopists with a poor $(<10 \%$ detection) baseline adenoma detection rate do not improve sufficiently using performance feedback and suggests that additional training is needed for these endoscopists. ${ }^{33}$

Recently, the EU has set forth comprehensive guidelines for quality assurance of endoscopy in CRC screening and diagnosis. ${ }^{34}$ The authors note that achieving an adequate volume of procedures is essential to maintaining skills and recommends 
an endoscopist volume of at least 300 colonoscopies per year. This is based on clear evidence that the risk of colonoscopy related bleeding and perforation is increased if the procedure is done by a low volume endoscopist. ${ }^{35}$

PCCRC occurs in a small but clinically important percentage of patients. Future research should be directed at disentangling the relative contributions of tumour biology and colonoscopy quality in explaining this result. By being aware of the circumstances in which PCCRCs occur, and by careful attention to colonoscopy quality, we should be able to reduce the risk of these unwelcome events.

\section{Competing interests None.}

Provenance and peer review Commissioned; externally peer reviewed.

\section{References}

1. Parkin DM, Bray F, Ferlay J, et al. Global cancer statistics, 2002. CA Cancer J Clin 2005;55:74-108.

2. Winawer SJ, Zauber AG, Ho MN, et al. Prevention of colorectal cancer by colonoscopic polypectomy. The National Polyp Study Workgroup. N Engl J Med 1993;329:1977-81.

3. Martínez ME, Baron JA, Lieberman DA, et al. A pooled analysis of advanced colorectal neoplasia diagnoses after colonoscopic polypectomy. Gastroenterology 2009;136: 832-41.

4. Loeve F, van Ballegooijen M, Boer R, et al. Colorectal cancer risk in adenoma patients: a nation-wide study. Int J Cancer 2004;111: 147-51.

5. Rex DK, Rahmani EY, Haseman JH, et al. Relative sensitivity of colonoscopy and barium enema for detection of colorectal cancer in clinical practice. Gastroenterology 1997;112:17-23.

6. Bressler B, Paszat LF, Chen Z, et al. Rates of new or missed colorectal cancers after colonoscopy and their risk factors: a population-based analysis. Gastroenterology 2007;132:96-102.

7. Singh H, Turner D, Xue L, et al. Risk of developing colorectal cancer following a negative colonoscopy examination: evidence for a 10-year interval between colonoscopies. JAMA 2006;295:2366-73.

8. Lakoff J, Paszat LF, Saskin R, et al. Risk of developing proximal versus distal colorectal cancer after a negative colonoscopy: a population-based study. Clin Gastroenterol Hepatol 2008;6:1117-21.

9. Baxter NN, Goldwasser MA, Paszat LF, et al. Association of colonoscopy and death from colorectal cancer: a population- based, case-control study. Ann Intern Med 2009;150:1-8.

10. Brenner $\mathrm{H}$, Hoffmeister $\mathrm{M}$, Arndt $\mathrm{V}$, et al Protection from right- and left-sided colorectal neoplasms after colonoscopy: population-based study. J Natl Cancer Inst 2010;102:89-95.

11. Rabeneck L, Paszat LF, Saskin R. Endoscopist specialty is associated with incident colorectal cancer following a negative colonoscopy. Clin Gastroenterol Hepatol 2010 (in press).

12. Shah HA, Paszat LF, Saskin R, et al. Factors associated with incomplete colonoscopy: a population-based study. Gastroenterology 2007;132:2297-303.

13. Bowles CJ, Leicester R, Romaya C, et al. A prospective study of colonoscopy practice in the UK today: are we adequately prepared for national colorectal cancer screening tomorrow? Gut 2004;53:277-83.

14. Aslinia F, Uradomo L, Steele A, et al. Quality assessment of colonoscopic cecal intubation: an analysis of 6 years of continuous practice at a university hospital. Am J Gastroenterol 2006;101:721-31.

15. Regula J, Rupinski M, Kraszewska E, et al. Colonoscopy in colorectal-cancer screening for detection of advanced neoplasia. N Engl J Med 2006;355:1863-72.

16. Rex DK, Bond JH, Winawer S, et al. Quality in the technical performance of colonoscopy and the continuous quality improvement process for colonoscopy: recommendations of the U.S. Multi-Society Task Force on Colorectal Cancer. Am J Gastroenterol 2002;97:1296-308.

17. Rostom A, Jolicoeur E, Dube C, et al. A randomized prospective trial comparing different regimens of oral sodium phosphate and polyethylene glycol-based lavage solution in the preparation of patients for colonoscopy. Gastrointest Endosc 2006;64:544-52.

18. Aoun E, Abdul-Baki H, Azar C, et al. A randomized single-blind trial of split-dose PEG-electrolyte solution without dietary restriction compared with whole dose PEGelectrolyte solution with dietary restriction for colonoscopy preparation. Gastrointest Endosc 2005;62:213-18.

19. Siddiqui AA, Yang K, Spechler SJ, et al. Duration of the interval between the completion of bowel preparation and the start of colonoscopy predicts bowel-preparation quality. Gastrointest Endosc 2009;69(3 Pt 2):700-6.

20. Pickhardt PJ, Nugent PA, Mysliwiec PA, et al. Location of adenomas missed by optical colonoscopy. Ann Intern Med 2004;141:352-9.

21. Atkin WS, Morson BC, Cuzick J. Longterm risk of colorectal cancer after excision of rectosigmoid adenomas. $N$ Engl J Med 1992;326:658-62.

22. Farrar WD, Sawhney MS, Nelson DB, et al. Colorectal cancers found after a complete colonoscopy. Clin Gastroenterol Hepatol 2006;4:1259-64. 
23. Pabby A, Schoen RE, Weissfeld JL, et al. Analysis of colorectal cancer occurrence during surveillance colonoscopy in the dietary Polyp Prevention Trial. Gastrointest Endosc 2005;61:385-91.

24. Morson B. President's address. The polypcancer sequence in the large bowel. Proc R Soc Med 1974;67:451-7.

25. Sawhney MS, Farrar WD, Gudiseva S, et al. Microsatellite instability in interval colon cancers. Gastroenterology 2006;131:1700-5.

26. Rembacken BJ, Fujii T, Cairns A, et al. Flat and depressed colonic neoplasms: a prospective study of 1000 colonoscopies in the UK. Lancet 2000;355:1211-14.

27. Soetikno RM, Kaltenbach T, Rouse RV, et al. Prevalence of nonpolypoid (flat and depressed) colorectal neoplasms in asymptomatic and symptomatic adults. JAMA 2008;299:1027-35.

28. Rex DK. Colonoscopic withdrawal technique is associated with adenoma miss rates. Gastrointest Endosc 2000;51:33-6.

29. Baxter NN, Sutradhar R, Forbes S, et al. Can quality indicators for colonoscopy be derived from administrative data? Identifying predictors of new or missed cancers after colonoscopy. Gastrointest Endosc 2009;69:AB120.

30. Barclay RL, Vicari JJ, Doughty AS, et al. Colonoscopic withdrawal times and adenoma detection during screening colonoscopy. $N$ Engl J Med 2006;355:2533-41.
31. Sawhney MS, Cury MS, Neeman N, et al. Effect of institution-wide policy of colonoscopy withdrawal time $\geq 7$ minutes on polyp detection. Gastroenterology 2008;135:1892-8.

32. Gupta R, Steinbach M, Ballman KV, et al. Colorectal cancer despite colonoscopy: critical is the endoscopist, not the withdrawal time. Gastroenterology 2009; 136 (Suppl 1):A-55.

33. Kaminski MF, Kraszewska E, Polkowski $\mathrm{M}$, et al. Continuous quality improvement of screening colonoscopy: data from a large colorectal cancer screening program. Gastrointest Endosc 2009;69:AB215.

34. Valori R, Rey J-F, Atkin W, et al. Guidelines for quality assurance of endoscopy in colorectal cancer screening (and diagnosis). In: Patnick J, Segnan N, Von Karsa L, eds. European guidelines for quality assurance in colorectal cancer screening. Lyon, France: IARC (in press).

35. Rabeneck L, Paszat LF, Hilsden RJ, et al. Bleeding and perforation after outpatient colonoscopy and their risk factors in usual clinical practice. Gastroenterology 2008;135:1899-906.

36. Winawer SJ, Zauber AG, Fletcher RH, et al. Guidelines for colonoscopy surveillance after polypectomy: a consensus update by the US Multi-Society Task Force on Colorectal Cancer and the American Cancer Society. Gastroenterology 2006;130:1872-85. 